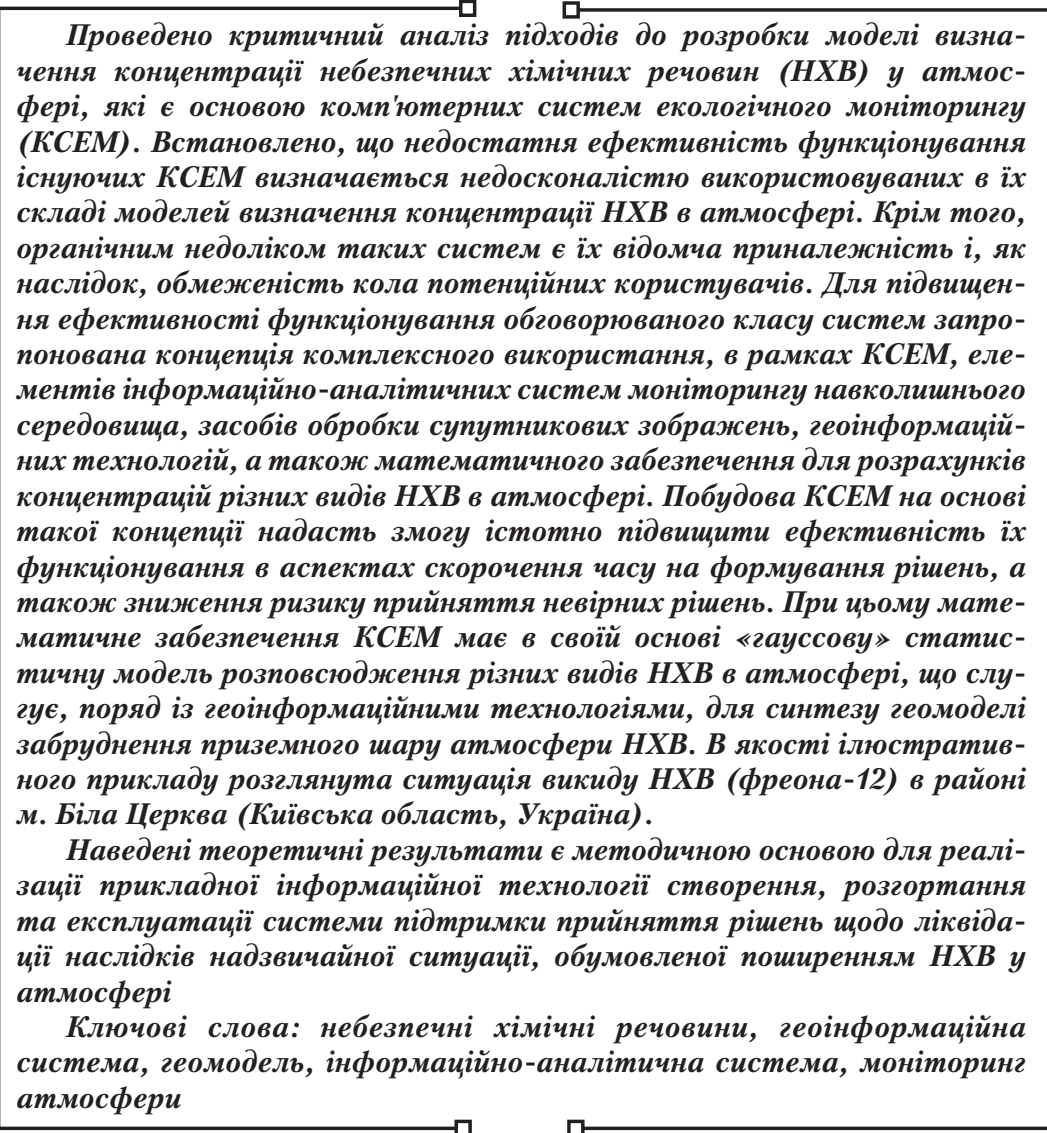

UDC 004.942

DOI: $10.15587 / 1729-4061.2018 .151650$

DEVELOPMENT OF GEO-MODEL FOR CONCENTRATION DETERMINATION OF HAZARDOUS CHEMICALS \section{IN THE ATMOSPHERE}

K. Thamer

$\mathrm{PhD}$

Department of computer science

Al Maaref University College 330 Ramadi, Anbar, Iraq, 31001

E-mail: Kder.abd@mail.ru

\section{Introduction}

The negative impact of the environment on the state of human health, due to anthropogenic stress, has increased many times in recent years. One of the most important factors of such exposure is atmospheric pollution with hazardous chemicals (HC), such as ash, industrial dust, zinc oxide, resins, oxide and nitrogen dioxide, ammonia, hydrogen chloride, etc.

The vast majority of modern computer systems for environmental monitoring (CEMS) are subordinate to the department. CEMS are focused on a comprehensive assessment of the current state of potentially hazardous objects (PHO) [1] and emergency situations at these facilities related to environmental pollution by chemical waste [2, 3].

At the same time, the systems of basic monitoring (as a rule, terrestrial), are able to track the background content in the air of a very limited $\mathrm{HC}$ range. Thus, the currently used computer systems for monitoring air pollution have a number of drawbacks, which significantly reduce their effectiveness.

These disadvantages include, first of all, the focus on decision-making support only in extreme conditions, and, by virtue of departmental affiliation, the limited number of potential users of such systems.

Today, in most countries of the world, a PHO classifier has been developed and operates, on the basis of which all PHOs are certified. In addition, the methods for calculating virtually all hazards, in particular, and those related to atmospheric pollution, have been developed and implemented as software tools. TOXI-3 methodology and others. On the other hand, today, the problem of creating effective means of risk assessment, determining the degree of vulnerability of the population due to atmospheric pollution of the chemical and water supply, remains topical.

The combination, within the framework of modern information and analytical environmental monitoring systems, of satellite image processing means with geoinformation technologies and mathematical software will provide an opportunity to provide a qualitatively new level of functioning of such systems. Along with this, the effectiveness of information and analytical systems for monitoring the environment would be much higher if CEMS had access to the hypermedia environment. Access to the information of many users would allow to adequately assess not only the collective but also the individual level of vulnerability, as well as significantly reduce the cost of operating atmospheric monitoring systems.

\section{Literature review and problem statement}

The issues of informatization of the monitoring processes of the state of the environment, in particular the atmosphere, using satellite monitoring and geoinformation technologies, are described in [4-8]. For example, in [4], the use of special tables is proposed, in which the standard values of the parameters of substances that are dangerous to the environment in general and to humans in particular are indicated. The authors of publications [5-8] describe the methods developed by them for calculating the area of infection and HC concentration. At the same time, in these publications, there are no results suitable for creating universal methodological and software tools for estimating the $\mathrm{HC}$ propagation, in 
each case the authors consider particular scenarios for the development of an emergency.

Since the processes HC propagation processes in the atmosphere are continuous, they are adequately representable in the form of a system of differential equations. At the same time, it is necessary to take into account a significant number of factors describing environmental conditions, which in practice leads to the representation of a model in the form of a system of high-order equations for which there are no computational methods that guarantee the existence and uniqueness of the solution. The representation of the processes under consideration by logical-dynamic equations is impossible due to the weak structuring of these processes, which leads to the need to use artificial intelligence technologies [9]. The authors of this work suggested using artificial neural networks as a methodological base for the created CEMS. As the components of the model, the authors proposed to use expert and fuzzy systems, genetic algorithms, fractals, elements of cognitive computer graphics. The authors of the work under discussion do not describe specific models and technologies in which the corresponding ideas are implemented. At the same time, the effective solution of problems of forecasting accidents and their consequences plays an important role in decision-making. In modern scientific literature, such problems are poorly represented and, as a rule, at the general theoretical level. For example, in [10] the process of macro-forecasting of information indices of environmental safety using the neural network model is described, and in [11] models are proposed for HC monitoring based on logical-probabilistic modeling. The results of the first of these works provide an opportunity to draw conclusions about the degree of danger of living in the region, while the models proposed in [11] allow to assess the risks of an emergency and possible scenarios of decision makers.

A significant part of modern work in this area is devoted to the study of the maximum concentration levels of explosive substances. In particular, the lower concentration limit of ignition, that is, the minimum content of fuel in a mixture of "combustible matter-oxidizing environment", is established in [12]. The authors of [13] believe that if the concentration is less than such a limit, then the conditions of the technological process should be safe. In [14] the solution of the same problem for open territories is proposed. The author of the above works focuses on the prediction of future events, while issues related to the assessment of accuracy and the adjustment of forecasts remain out of the view of researchers.

Prediction of $\mathrm{HC}$ concentration in the atmosphere is accompanied by considerable uncertainty. For a quantitative description of the HC propagation process, today there are three known approaches based on the use of: Gaussian or dispersive models; dispersion models that use integral mass conservation laws in the cloud for salvo emissions, but also include so-called "heavy gas" models, as well as direct numerical simulation models.

In Gaussian models, a series of heuristics is introduced to determine the coefficients describing atmospheric turbulence. The models themselves describe two processes in the atmosphere - wind and the HC dispersion due to atmospheric turbulence. The disadvantage of such models is the relatively low accuracy of estimating the $\mathrm{HC}$ concentration near the point of release. The dynamics of propagation of atmospheric chemical compounds in the atmosphere during emission is much more complicated than it is represented in Gaussian models, since this type of models does not take into account reduced currents and an increased density of chemical atmospheric compounds compared to atmospheric air. Therefore, special models are developed that take into account the HC relevant features and which are called the "heavy gas" dispersion models. The implementations of such models are known: the World Bank methodology [15], HGGYSTEM [16], presented in GOST R12.3.047-98 [17], the RD method 52.04.253-90 [18]. The common drawbacks of the above methodical means are the exaggerated real consequences of accidents.

Thus, the unresolved at the moment the problems of creating CEMS for assessing the effects of technological and environmental accidents and disasters associated with the HC propagation in the atmosphere should include:

1. The lack of a unified approach to the development of a methodological framework and the practical implementation of technologies that take into account both the continuous dynamics of environmental change and the decision maker's subjectivity.

2. The lack of methods to prevent accidents and disasters by predicting emergency situations.

3. The lack of elements of scenario analysis and, as a result, decision-making on the fact of an accident, when in a critical situation the risks of making decision makers significantly wrong.

4. In the case of decision-making by a team of experts, a necessity to take into account the different levels of competence of those involved in this process, which is not always possible.

Of the problems listed above, the first one is the most significant at the moment, since the lack of a methodological basis prevents the effective overcoming of the rest. At the same time, the features of chemical accidents and their consequences determine the need to solve the scientific and technical problem of predicting the $\mathrm{HC}$ concentration in the entire contamination area. To solve this problem, it is necessary to obtain models that allow determining the HC concentration in the entire possible area of infection or the $\mathrm{HC}$ concentration values at specific points.

\section{The aim and objectives of research}

The aim of research is increasing the efficiency of the process of determining the $\mathrm{HC}$ concentration in the atmosphere based on the improvement of the computer system for environmental monitoring. This will allow analyzing and assessing the level of vulnerability of the population due to air pollution with hazardous chemicals.

Achieving this aim is associated with the necessity to solve the following tasks:

- synthesize, on the basis of evolutionary modeling methods, a methodology for predicting the concentration of hazardous chemicals in the post-accident period;

- develop a special geo-model based on the combination of analytical methods and geoinformation technologies, in order to accurately determine the hazardous areas when $\mathrm{HC}$ emissions into the atmosphere;

- illustrate the result of using the synthesized method for creating a core, in the form of a geo-model, a computerized environmental monitoring system, using the example of estimating the HC propagation after a chemical accident in the area of Bila Tserkva, Ukraine. 
4. Materials and methods for studying the characteristics of the process of determining the $\mathrm{HC}$ concentration in the atmosphere

At the substantive level, the aim of research is prediction the HC concentration in the post-accident period on the basis of preliminary pre-emergency structural and parametric identification of the models of the $\mathrm{HC}$ concentration and to refine its values based on the results of several measurements.

To implement the task formulated above, it is necessary to create a system for predicting the $\mathrm{HC}$ concentration in the post-accident period, which makes it possible, on the basis of this information, to rationally allocate resources for emergency response.

Since the determination of the $\mathrm{HC}$ concentration is carried out in the post-accident period, the criticality of the conditions, the responsibility for the decisions made, does not allow the use of a set of reasonable measures to minimize the consequences of the accident. For the objectification of such decisions it is necessary to use both monitoring and prediction data.

Prediction of the consequences of the accident occurs under conditions of uncertainty caused by their suddenness and critical decision-making processes. In practice, there are operational, tactical and strategic types of prediction

In the first case (operational forecasting), determine the scale of the accident and the expected consequences in the near future (3-5 hours). Tactical prediction is designed to provide answers to questions about the area of infection, the necessity to evacuate people, possible damage and the actions of the operational and rescue services. The timing of the elimination of the consequences of the accident, its impact on the environment, the quantitative and qualitative composition of technical means is the subject of strategic forecasting. It is also necessary to implement post-forecasting or specification of the values of the parameters of a chemical accident in the post-accident period.

Since traditionally relevant forecasting problems in this case are solved using well-known methods based on the principle of averaging the results, it is often impossible to obtain accurate results in every situation that is unique. In this case, it is necessary to use models in which the environmental features are adequately represented. It is obvious that the construction of such models should be based on the consideration of expert experience.

Models for determining the HC concentration are identified in the pre-accident period and it is obvious that the simulation results will not fully reflect the features of a specific accident. Refinement could be made taking into account the insignificant number of measurements in the post-accident period, since measurements are anyway taken. In this case, there is the possibility of rational retraining of the model in an accelerated mode. In addition, the measurement results will allow to clarify the initial values of the accident parameters, which are set for calculations using the model empirically. Features of the solution of the problem require the use of an appropriate mathematical apparatus, which would make it possible to take into account the expert opinions and accelerated correction of the HC concentration model.

Since the output exact values of the accident parameters are unknown, these parameters are determined as a result of expert conclusions. On their basis, subsequent decisions are made. It is obvious that if the accuracy of such conclusions is low, then the effectiveness of the decisions made will be low. Therefore, it is necessary to carry out point measurements of the $\mathrm{HC}$ concentration in the reference points, and on the basis of them to carry out the correction of decision-making processes.

In the period of time preceding the accident, it is necessary to identify the dependence

$$
\mathrm{C}=F(P),
$$

where $C$ - HC concentration, $P$ - vector of parameters and factors.

In this case, $\mathrm{P}$ has the following structure:

$$
P=\left(x_{0}, y_{0}, z_{0}, t_{0}, x, y, z, t, M, W, D, T, V, R, U\right)
$$

where $\left(x_{0}, y_{0}, z_{0}, t_{0}\right)$ - the coordinates of the point and time of the accident, $(x, y, z, t)$ - the coordinates of the point at which the HC concentration is determined, and the appropriate time; other parameters of the accident are given by constants.

Another aspect of the problem of predicting the propagation of atmospheric chemical waste in the atmosphere is the probability of multiple exceeding the maximum allowable concentration of atmospheric chemical agents. In this regard, it is advisable to take into account the general provisions of the theory of catastrophes [19]. The dynamics of the corresponding process is shown in Fig. 1.

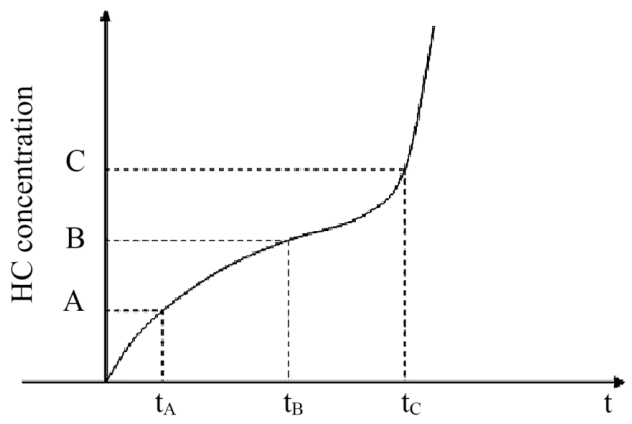

Fig. 1. Dynamics of $\mathrm{HC}$ atmospheric concentration

In Fig. 1, points are a number of events occurring during the propagation of atmospheric chemical explosives in the atmosphere. Event A - HC concentration has reached a dangerous level and it is necessary to take measures to reduce it. Event B - the point preceding the catastrophe, since at the moment of time $t_{B}$ the catastrophe, in most cases, can't be stopped due to the inertia of the process of increasing the HC concentration. Event C - a catastrophe point, after which the increase in the concentration of a substance takes the form of a quadratic or exponential dependence.

When creating the database, it is necessary to take into account the fact that the processes at the sites $\left(0, t_{A}\right),\left(t_{A}, t_{B}\right)$, $\left(t_{B}, t_{C}\right),\left(t_{C}, \ldots\right)$, are diffused. Taking into account the characteristics and experience of experts, allow for the implementation of control actions to prevent disasters.

The existing methods for determining the calculation of $\mathrm{HC}$ propagation areas make it possible to calculate the size and area of the contamination area, the time of approach of a cloud of contaminated air to a specific object, the time of the impact and possible losses.

Another problem is the change in the nature of the weather conditions in the area of HC propagation (Fig. 2). 


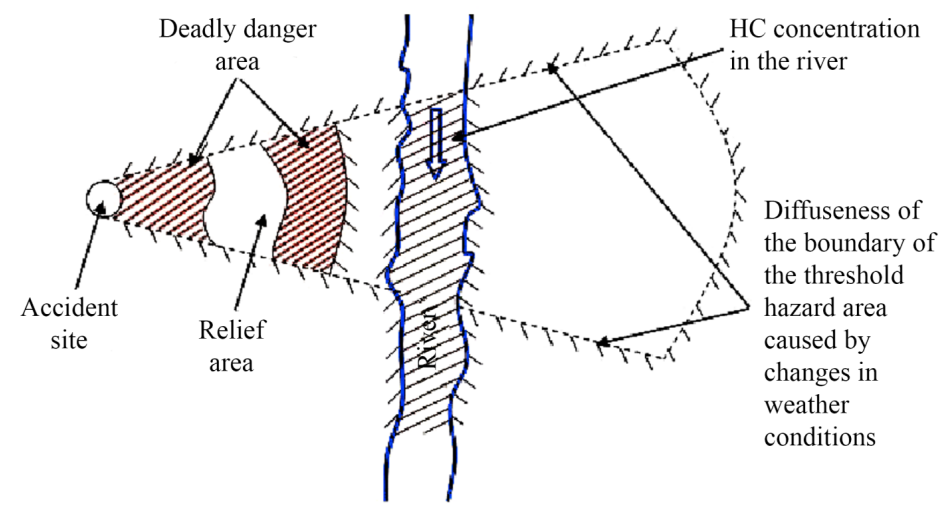

Fig. 2. HC contaminated area

Mathematical modeling of the HC propagation processes in the atmosphere is based on taking into account such characteristics as the parameters of emission sources, wind direction and speed at the time of emission, the nature of the terrain and the terrain development.

The process of propagation of emissions in the atmosphere occurs due to the advent of HC propagation by the air mass and diffusion caused by both the HC physical properties and air mass turbulence. Observation of the cloud shows that at first the cloud at the exit from the source is picked up by air masses at a certain height with its gradual expansion when moving away from the source as a result of small-scale turbulence flows. Then, gradually increasing, the ejection cloud disintegrates into isolated vortex formations that are transported long distances from the source. Gaseous poisons that enter the atmosphere can interfere with each other in photochemical reactions.

4. 1. Synthesis of a geo-model for the determination of hazardous areas when $\mathrm{HC}$ emissions into the atmosphere

The basis of the developed technology for the synthesis of a geo-model of pollution of the surface layer of the atmosphere by $\mathrm{HC}$ emissions is based on a mathematical model of the dispersion of pollutants in the atmosphere [20].

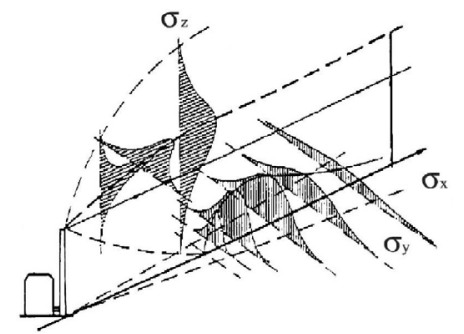

Fig. 3. Representation of the model of the $\mathrm{HC}$ torch emission in space

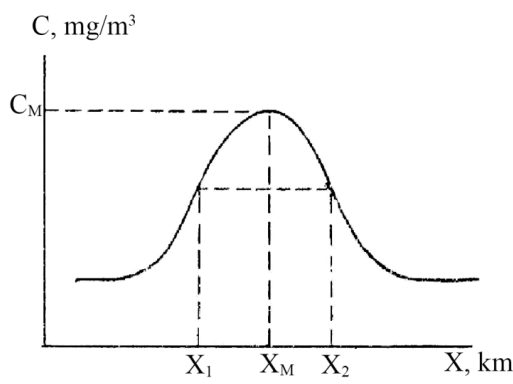

Fig. 4. Representation of the model of the $\mathrm{HC}$ torch emission on the plane
This model contains information on the surface source of $\mathrm{HC}$ emissions, which is presented as a round hole with a $20-30$ minute leakage averaging. In this case, the HC maximum concentration $C_{M}\left(\mathrm{mg} / \mathrm{m}^{3}\right)$ is reached at a distance $X_{M}(\mathrm{~m})$ from the source and is determined by the formula:

$$
c_{M}=\frac{A M F m n \eta}{H^{2} \sqrt[3]{V_{1} \Delta T}},
$$

where $A$ - the coefficient of temperature stratification of the atmosphere; $M(\mathrm{~g} / \mathrm{s})$ - the mass of HC flowing in a unit of time; $\mathrm{F}$ - dimensionless coefficient, taking into account the rate of HC sedimentation in atmospheric air; $\mathrm{m}$ and $n-\mathrm{HC}$ leakage coefficients: $\mathrm{H}(\mathrm{m})$ - the height of the emission source above surface level, for terrestrial sources $H=2 \mathrm{~m}$; $\eta$ - the dimensionless coefficient of influence of the terrain; $\Delta T\left({ }^{\circ} \mathrm{C}\right)$ - the difference between the $\mathrm{OHV} \mathrm{HC}$ emission temperature $T_{G}$ and the atmospheric air temperature $T_{A} ; \mathrm{V}_{1}\left(\mathrm{~m}^{3} / \mathrm{s}\right)$ - HC volume entering the atmospheric air for $1 \mathrm{sec}$. The values of the individual coefficients are calculated using the formulas and tables given in [1]

In the absence of wind and a value of $\eta=1$, the character of the spatial propagation of the concentration of a certain HC type is illustrated in Fig. 5.

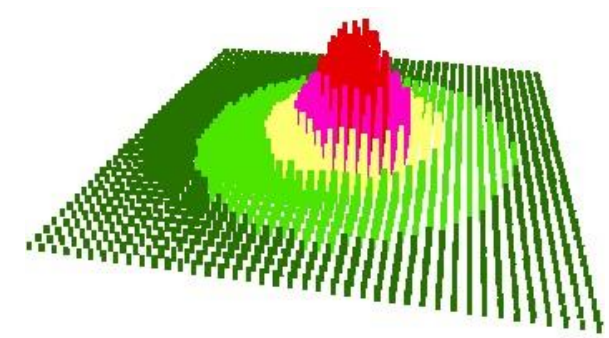

Fig. 5. The propagation of $\mathrm{HC}$ concentrations in the surface layer of the atmosphere

In the two-dimensional dimension, such a character of the $\mathrm{HC}$ concentration, in the surface layer of the atmosphere under the condition of the absence of wind and on flat terrain without buildings and forest plantations with a height difference of up to $50 \mathrm{~m}$ per $1 \mathrm{~km}$.

In the synthesis of a mathematical model [20], it is necessary to take into account the parameters of factors that influence the patterns of $\mathrm{HC}$ propagation in atmospheric air, namely: the nature of the relief, features of terrain development, direction and speed of surface wind. At the same time, the spatial propagation of the $\mathrm{HC}$ concentration will differ significantly from concentric circles, and will have the shape of an emission torch.

The direction of the torch axis depends on the wind direction, and the propagation of OHV concentrations along and across the axis depends on its speed.

The initial data, the direction and speed of the wind, are determined from the data of long-term observations at meteorological stations, which are common in the corresponding terrain.

4. 2. Technique for predicting the concentration of hazardous chemicals in the post-accident period based on evolutionary modeling methods

The above circumstances determine the necessity to develop a special method of calculation, based on the Gaussian 
model, the concentration of atmospheric chemical concentration in the atmosphere, at certain points of the propagation area. This technique was developed using evolutionary modeling in the form of directional optimization.

The method of directed optimization is based on the idea of optimizing the process of randomly searching for the optimal solution using evolutionary algorithms. These algorithms are a composition of several techniques: elements of evolutionary strategies, a method for analyzing hierarchies, and elements of the theory of fuzzy sets.

The developed technique implements the solution of the next search task.

$$
\max _{X \in \Omega} f(X),
$$

where $X=\left(x_{1}, x_{2}, \ldots, x_{n}\right), \Omega$ - some hyper-parallelepiped.

The technique includes the following steps:

Step 1. Determination of the initial number of potential solutions $\lambda$ and generation of uniformly distributed potential solutions $z_{1}^{e}, z_{2}^{e}, \ldots, z_{\lambda}^{e}$. in the space $\Omega$

Step 2. Calculation of the function $f$ value in points $z_{1}^{e}, z_{2}^{e}, \ldots, z_{\lambda}^{e}$ :

$$
f_{1}^{e}=f\left(z_{1}^{e}\right), f_{2}^{e}=f\left(z_{2}^{e}\right), \ldots, f_{\lambda}^{e}=f\left(z_{\lambda}^{e}\right) .
$$

Step 3. Rationing the value $f_{j}^{e}$ by checking the condition $f_{j}^{n e} \in[0 ; 1]$,

$$
\sum_{i=1}^{\lambda} f_{j}^{n e}=1
$$

Step 4. Formation of the matrix of Saaty pairwise comparisons S: among the normalized values of the function, finding the minimum value $f_{j}^{n e}$, of the segment $[0 ; 1]$ decomposition into 10 intervals: $[0 ; 0,1),[0,1 ; 0,2), \ldots,[0,9 ; 1]$. Then for all values of the function $h \in\{1,2, \ldots, \lambda\}$, , if

$$
f_{j}^{n e} \in[0,1 k ; 0,1+0,1 k) \text { and } f_{h}^{n e} \in[0,1 l ; 0,1+0,1 l),
$$

where $k, l \in\{0,1, \ldots, 9\}$, then $s_{j h}=l-k+1$. Other elements of the matrix $\mathrm{S}$ are calculated by the formula:

$$
s_{p q}=\frac{s_{j q}}{s_{j p}} .
$$

Step 5. Calculation of the eigenvalues of the matrix S, and for the maximum eigenvalue $a_{\max }$ finding the vector by the formula:

$$
w_{j}=\frac{1}{s_{1 j}+s_{2 j}+\ldots+s_{\lambda j}} .
$$

The value $w_{j}$ indicates the degree of optimality (quasi-optimality) of the potential solution $z_{j}^{e}$.

Step 6. Generation of "descendants" and the formation of a new population of potential solutions. In accordance with the evolutionary strategy, in this case, the formula is used:

$$
z_{j}^{e+1}=z_{j}^{e}+\xi(N(0,1)), \quad j=\overline{1, \mu}
$$

where $\xi(N(0,1))$ - normally distributed random variable with zero mean and unit variance; $\eta$ - the number of "descendants" of one "parent". In practice, it is advisable to take $\mu \geq 7 \lambda$.
Step 7. Calculation of the optimality degree $w_{j}$ of potential solutions $z_{j}^{e}$ for the study of the region $\Omega$, in order to determine the largest possible number of points of $\mathrm{HC}$ atmospheric propagation area.

Step 8. Determination of the number of descendants depending on the optimality of the obtained solution. The number of descendants $N\left(z_{j}^{e}\right)$ depends on the area degree $\Omega$ and the given accuracy of the potential solution $\varepsilon$. For the case when $\Omega$ is the segment

$$
N\left(z_{j}^{e}\right)=g(L([a, b])),
$$

where $L\left(^{*}\right)$ - the segment length. Determination of the value $\mu_{j}$ is made in a heuristic way, based on expert conclusions. At the first stage it is rational to assume that $\mu_{j}=\mu$ $\forall i \in\{1,2, \ldots, \lambda\}$.

Step 9. Determination of the dispersion value for each solution obtained at the previous steps. The dispersion value $\sigma_{j}^{2}$ will depend on $L([a, b])$ and $\varepsilon$, as well as on the distance to the nearest neighboring solutions.

Step 10. Finding $d\left(z_{j}^{e}, z_{L}\right), d\left(z_{j}^{e}, z_{R}\right)$ - the distance to the nearest left (point a) and right (point b) of adjacent solutions. Wherein

$$
d_{\max }=\max \left\{d\left(z_{j}^{e}, z_{L}\right), d\left(z_{j}^{e}, z_{R}\right)\right\},
$$

then, according to the 3 -sigma rule $\sigma_{j}=\frac{1}{3} d_{\max }, 9973$ points out of 10,000 when generating will belong to the interval $\left(x_{j}^{e}-3 \sigma_{j}, x_{j}^{e}+3 \sigma_{j}\right)$.

Step 11. Determination, on the basis of the obtained values of the function $\mathrm{f}$, and also on the values $f_{1}^{e}, f_{2}^{e}, \ldots, f_{\lambda}^{e}$, to find $\lambda$ of the optimal solutions $z_{1}^{e+1}, z_{2}^{e+1}, \ldots, z_{\lambda}^{e+1}$ and go to step 1.

The result of applying the technique described above is obtained when performing some e-th iteration, when the value $\max _{i, j}\left|f_{i}-f_{j}\right|, i, j=\overline{1, \lambda}$ is less than some predetermined value $\delta^{i, j}>0$. In this case $\max _{i, j}\left|z_{j}^{e}-z_{i}^{e}\right|<\varepsilon$. Then the value $z_{i}^{v}$ corresponding to $f_{i}^{e}=\max _{j} f_{j}^{e}$ will be the solution of the problem.

The calculated values are used in the environment of a geoinformation system in the generation of a digital layer that simulates the area of $\mathrm{HC}$ propagation in the atmosphere.

4. 3. Results of a field experiment assessing the HC propagation in the atmosphere, based on a geo-model, due to a chemical accident in the area of Bila Tserkva, Ukraine

Today there are a number of actually functioning geographic information systems (GIS), implemented in the framework of the concept of effective management of territorial development (TDM) [21].

Information resources of TDM GIS, in general, include the following main components:

- software and hardware complex - GIS platform;

- topographic basis;

- base attribute data on GIS objects management;

- subject-oriented thematic cartographic models.

The problem of information support of decisions on the issues of mitigation and planning of measures for the prevention of emergency situations associated with the HC emissions is implemented in the shell of the TDM GIS subject-oriented subsystem. This system is called the emission 
management subsystem (EMS). EMS in practice is used not only to monitor HC air emissions in emergency situations, but also to inventory emission sources of all industrial enterprises in a certain area.

The composition of the subject-oriented thematic cartographic models of the EMS subsystem for each potentially hazardous enterprise includes the geo-model of the $\mathrm{HC}$ pollution in the event of their likely release in the absence of wind - calm. Below is an example of a geo-model (Fig. 6).

In emergency situations related to $\mathrm{YC}$ emissions into the atmosphere, decisions on emergency response should be taken with significant time limits for analyzing the course of events. When planning measures for the prevention of emergency situations with the specified consequences, there are no critical time constraints.

Therefore, in the first case, for each potentially hazardous object, it is advisable to have a pre-calculated geo-model of contaminated areas with the most likely parameters of meteorological conditions.

For this it is necessary to use the results of the analysis of data on the repeatability (\%) of wind directions by points and their average monthly speeds - Fig. 6 for the area where the corresponding potentially dangerous object is located.

As evidenced by the analysis of data in Fig. 6, for the area considered in the previous example, Bila Tserkva, four characteristic wind speeds can be distinguished, namely: $3.75 ; 3.5 ; 3.0 ; 2.5 \mathrm{~m} / \mathrm{s}$. Each of them has the corresponding characteristics of the torch ejection, which is considered in a rectangular three-dimensional space XYZ. The center of coordinates is located in the center of the emission source, the $\mathrm{X}$ axis coincides with the rumba of the wind, the $\mathrm{Z}$ axis is the vertical of the XOY plane - Fig. 7. The HC concentration at an arbitrary point of the torch area is calculated according to the formulas given in [20], taking into account the features of the terrain.

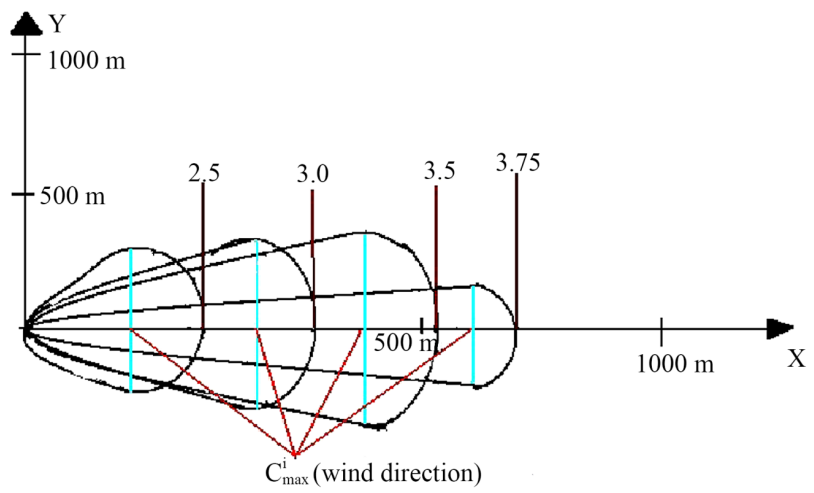

Fig. 7. Projection of the PC torch emission on the plane, calculated on the basis of the directed optimization method

$\mathrm{C}_{\max }\left(\mathrm{mg} / \mathrm{m}^{3}\right)$ concentration $\mathrm{C}_{\mathrm{Mx}}$, at a distance $\mathrm{x}$ from the source of emission at a given wind speed along the torch axis.

Usually, the calculation of $\mathrm{HC}$ concentrations in the ejection torch area is performed with incremental increments of elevations along the $\mathrm{X}$ axis. For example, at a distance of $500 \mathrm{~m}$ every $100 \mathrm{~m}$, and then after $500 \mathrm{~m}$ or more.

The calculation of HC concentrations in the directions of the $\mathrm{Y}$ and $\mathrm{Z}$ axes is relative to the distance from the torch axis. In this case, $\mathrm{C}_{\max }\left(\mathrm{mg} / \mathrm{m}^{3}\right)$ of the $\mathrm{HC}$ concentration at a distance $\mathrm{x}$ from the source of emission at a given wind speed along the torch axis.

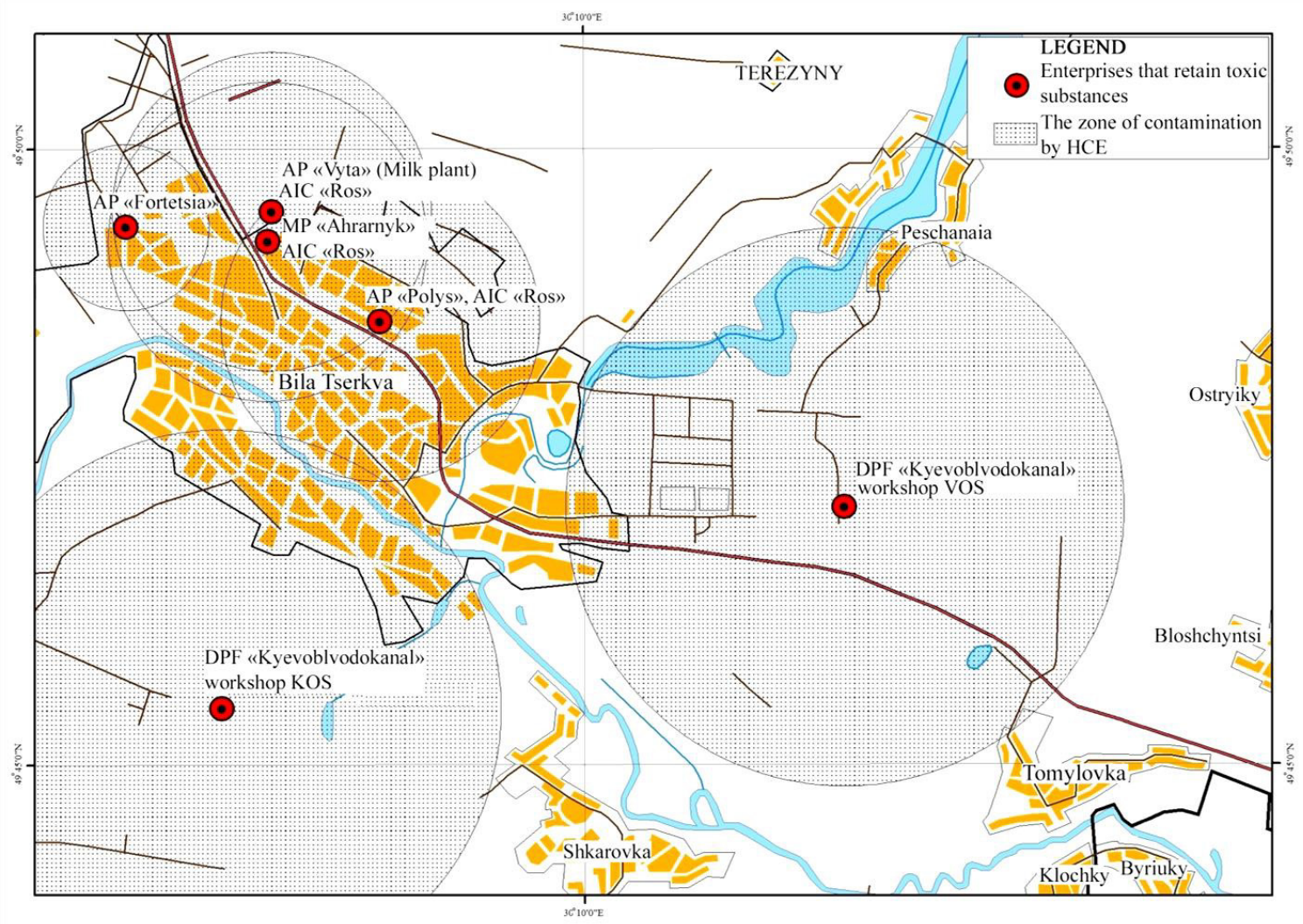

Fig. 6. Geo-model of probable HC pollution (neighborhood of Bila Tserkva, Ukraine) in the case of emissions from PHO 
To determine the effectiveness of the developed methodology using a geo-model, a comparative analysis is performed with the calculated results using other methods. At the same time, specific values obtained for a series of Freon-12 emissions from a tank at the PHO in the vicinity of Bila Tserkva, Ukraine were taken as a basis:

- emission volume of $2000 \mathrm{~m}^{3}$ or volumetric emission rate of $4.3 \mathrm{~m}^{3} / \mathrm{s}$;

- proportion of Freon in the gas mixture $-31 \%$;

- wind speed $-2.1 \mathrm{~m} / \mathrm{s}$;

- atmosphere stability E/F.

- total duration of the emission - about $400 \mathrm{~s}$.

In the course of the accident, about two dozen of salvo emissions of Freon-12 gas, both pure and diluted with air, occurred. After the ejection, the cloud of gas had the shape of a cylinder, the volume of which was about $2000 \mathrm{~m}^{3}$. The main characteristics of each series of $\mathrm{HC}$ emissions and the dispersion conditions are as follows: the average content in the atmosphere of Freon is $12-24 \%$, while the value of Freon-12 concentration in the atmosphere along the wind axis is given in Table 1.

To determine the HC concentration in the post-accident period, the initial data are the results of analytical calculations, adjusted for expert opinions. When building the geo-model, the data obtained from 64 expert opinions and simulation results using different values of the initial volume of Freon-12, the percent of its dilution, wind speed and atmosphere stability, reduced to numerical form, are used. The experiment also assumed that, up to $500 \mathrm{~m}$ from the source of the accident, the environmental conditions coincided with the conditions at PHO, and after $500 \mathrm{~m}-$ building and plantings are taken into account.

Table 1

The results of the experiment to determine the Freon-12 concentration in the atmosphere during an accident at a $\mathrm{PHO}$ in the neighborhood of Bila Tserkva

\begin{tabular}{|c|c|c|c|c|c|c|c|}
\hline$X, \mathrm{~m}$ & 70 & 100 & 150 & 180 & 220 & 350 & 500 \\
\hline$C, \%(\mathrm{v})$ & 3,1 & 1,35 & 0,8 & 0,6 & 0,45 & 0,28 & 0,14 \\
\hline
\end{tabular}

Table 2 shows the values of Freon-12 concentration in three control points (Avg) of the accident area.

relative accuracy is $1.7 \%$, and for the points located beyond the $500 \mathrm{~m}$ line, the accuracy is $3.6 \%$.

\section{Discussion of the results of the conducted research on the peculiarities of the process of determining the $\mathrm{HC}$ concentration in the atmosphere}

The proposed integrated approach to the modeling of processes associated with the HC propagation in the atmosphere has an important distinguishing feature. It consists in the fact that this approach combines geoinformation technologies, means of expert analysis and mathematical software, improved by applying methods of directional optimization.

The usefulness of the theoretical results is increasing the effectiveness of decisions made to prevent emergencies and overcome their consequences by reducing the uncertainty level in determining the current state of the $\mathrm{HC}$ propagation processes in the atmosphere. For example, as a result of the hypothetical HC release at the PHO "JSC "Fortetsia"” with damage to the Freon tank (Bila Tserkva, Ukraine), specifying the dangerous $\mathrm{HC}$ concentration zone would save time and financial resources when evacuating the population from the accident zone. This effect is achieved by taking into account a large number of heterogeneous factors that determine the dynamics of the considered process, and the possibility of clarifying the boundaries of $\mathrm{HC}$ dangerous concentration zones.

The advantage of the obtained results over the known solutions consists in the complex use of adequate mathematical apparatus and geoinformation technologies. The methodical tools used in practice use either a purely analytical approach or only geoinformation technologies. In the first case, there is a problem of dimension and heterogeneity, and in the second, an approximate representation of the HC propagation area in the form of a set of simple geometric figures.

The implementation of a geo-model for a scenario example makes it possible to obtain predicted values with an average relative deviation of $2.2-6.3 \%$, which is a significantly better result compared to those obtained using other methodological tools (Gaussian model, Toxi-3 methodology). ). Table 2 for its implementation it is necessary to Results of modeling the $\mathrm{HC}$ concentration at various points in the accident area have a well-developed structure of stations

\begin{tabular}{|c|c|c|c|c|c|c|c|}
\hline \multicolumn{5}{|c|}{ Concentration, \% } & \multicolumn{3}{|c|}{ Calculation time } \\
\hline \multicolumn{2}{|c|}{$\begin{array}{c}\text { Neighbor- } \\
\text { hood of Bila } \\
\text { Tserkva }\end{array}$} & \multirow[t]{2}{*}{$\begin{array}{c}\text { Gaussian } \\
\text { model }\end{array}$} & \multirow[t]{2}{*}{$\begin{array}{l}\text { Toxi-3 } \\
\text { technique }\end{array}$} & \multirow{2}{*}{$\begin{array}{c}\text { Targeted } \\
\text { optimization } \\
\text { technique }\end{array}$} & \multirow[t]{2}{*}{$\begin{array}{c}\text { Gaussian } \\
\text { model }\end{array}$} & \multirow[t]{2}{*}{$\begin{array}{l}\text { Toxi-3 } \\
\text { technique }\end{array}$} & \multirow{2}{*}{$\begin{array}{l}\text { Targeted } \\
\text { optimi- } \\
\text { zation } \\
\text { technique }\end{array}$} \\
\hline $\max$ & Avg & & & & & & \\
\hline 12 & 9,5 & 42 & 13 & 9,71 & \multirow{3}{*}{12} & \multirow{3}{*}{36} & \multirow{3}{*}{134} \\
\hline 9 & 8 & 14 & 7,8 & 8,04 & & & \\
\hline 1 & 0,6 & 4,5 & 0,85 & 0,59 & & & \\
\hline
\end{tabular}
for ground-based monitoring of the state of the atmosphere at the locations of numerous PHOs, which requires significant financial costs.

In the future, on the basis of the proposed approach, it is planned to develop a universal software environment that allows the creation of appropriate decision support systems. However, for the application of the developed technology in the tasks of pre-

The simulation was performed using the Gaussian model in combination with the algorithms of directional evolutionary modeling. Analysis of the results shows that the prediction accuracy is (average relative error) $3.4 \%$. In the simulation, the conclusions of five experts on 54 variants of the accident parameters are used.

At the control points located at a distance of 100, 150, $350 \mathrm{~m}$ from the center of the accident at PHO, the average dicting the concentration of not only Freon-12, but also other HC types, as well as their mixtures, it is necessary to conduct additional studies in the direction of taking into account the physicochemical characteristics of these substances, as well as the effects arising from their mixing. The latter circumstance is due to the existence of a number of problems that have not been solved at this stage and are not directly related to information technology. 


\section{Conclusions}

1. Improvement of mathematical tools for calculating the $\mathrm{HC}$ concentration in the atmosphere makes it possible to create a special technique that, unlike the existing ones, combines classical tools (Gaussian model) and methods of directional optimization (using elements of evolutionary strategies, methods of analyzing hierarchies and elements of fuzzy theory sets). The advantage of this technique is obtaining data on the $\mathrm{HC}$ concentration in many points of their propagation. The correlation of these data with the values of the maximum allowable concentration makes it possible to clarify the boundaries of the area of HC propagation.

2 . By combining analytical methods with geoinformation technologies, a geo-model is developed to implement information support technology for planning solutions for coping with the consequences of emergency situations involving $\mathrm{HC}$ in the atmosphere. This model is a complex of cartographic and analytical modeling tools, which is characterized by the use of a database of attributive data on sources and meteorological conditions at the time of release, as well as the use of software services of geoinformation systems.

3. The efficiency of using the methodology for calculating the $\mathrm{HC}$ concentration in the atmosphere using a geo-model is evaluated by comparing the calculation results based on the classical, Gaussian model, and the standard Toxi-3 method. The results of the field experiment show that the developed methodological tools provide, in comparison with the classical, greater accuracy of calculations. In particular, the average relative error in determining the $\mathrm{HC}$ concentration in the entire accident zone is $3.4 \%$. At the same time, at the control points located at a distance of 100, 150,350 m from the center of the accident, the average relative accuracy is provided at the level of $1.7 \%$, and for the points located beyond the line at $500 \mathrm{~m}$ - at the level of $3.6 \%$.

\section{References}

1. On the Use of Unmanned Aerial Systems for Environmental Monitoring / Manfreda S., McCabe M., Miller P., Lucas R., Pajuelo Madrigal V., Mallinis G. et. al. // Remote Sensing. 2018. Vol. 10, Issue 4. P. 641. doi: https://doi.org/10.3390/rs10040641

2. Tekhnicheskie aspekty sozdaniya kompleksnoy avtomatizirovannoy informacionnoy sistemy intellektual'nogo monitoringa okruzhayushchey sredy / Fayzrahmanov R. A., Slautin Yu. A., Volodin V. D., Bikmetov R. R., Sharonov A. A. // Ustoychivoe razvitie. 2013. Issue 10. P. $67-72$.

3. Tang R., Bai Y., Wang T. Research on GIS Application System of Environmental Risk for Hazardous Chemicals Enterprises // Procedia Environmental Sciences. 2011. Vol. 10. P. 1011-1016. doi: https://doi.org/10.1016/j.proenv.2011.09.162

4. Klochkova L. V., Orlov Yu. N., Tishkin V. F. Matematicheskoe modelirovanie korrelyacii epidemicheskoy obstanovki v megapolisah ot sostoyaniya vozduha // Zhurnal Srednevolzhskogo matematicheskogo obshchestva. 2012. Vol. 14, Issue 2. P. 34-43.

5. Zhu Y. Research on Application of Internet of Things in the Disposal of Environmental Emergency // MATEC Web of Conferences. 2015. Vol. 22. P. 04011. doi: https://doi.org/10.1051/matecconf/20152204011

6. Research on a 3D Geological Disaster Monitoring Platform Based on REST Service / Leng X., Liu D., Luo J., Mei Z. // ISPRS International Journal of Geo-Information. 2018. Vol. 7, Issue 6. P. 226. doi: https://doi.org/10.3390/ijgi7060226

7. Development of a Web-based GIS monitoring and environmental assessment system for the Black Sea: application in the Danube Delta area / Tziavos I. N., Alexandridis T. K., Aleksandrov B., Andrianopoulos A., Doukas I. D., Grigoras I. et. al. // Environmental Monitoring and Assessment. 2016. Vol. 188, Issue 8. doi: https://doi.org/10.1007/s10661-016-5492-z

8. Rybka N. A. Metodika ocenki masshtabov i posledstviy vybrosov (prolivov) avariyno himicheski opasnyh veshchestv // Vestnik VGU. Ser.: Himiya, biologiya, farmaciya. 2014. Issue 2. P. 37-40.

9. Metody i modeli analiza dannyh: OLAP i Data Mining / Barsegyan A. A. Kupriyanov M. S., Stepanenko V. V., Holod I. I. SanktPeterburg: BHV-Peterburg, 2004. 336 p.

10. Roshchupkin E. V. Neural-network forecasting model of pollution of atmospheric air // Izvestiya Tul'skogo gosudarstvennogo universiteta. Tekhnicheskie nauki. 2010. Issue 4. P. 266-271.

11. Mosyagin A. A. Monitoring potencial'no opasnyh ob'ektov na osnove logiko-veroyatnostnogo modelirovaniya: diss. ... kand. tekhn. nauk. Moscow, 2009. $212 \mathrm{p}$.

12. Biloshytskyi M. V. Vyznachennia vybukhonebezpeky vyrobnychykh prymishchen za nadkhodzhennia do nykh horiuchykh haziv abo pariv horiuchykh ridyn // Naukovyi zbirnyk Instytutu derzhavnoho upravlinnia u sferi tsyvilnoho zakhystu. 2013. Issue 1. P. 97-103.

13. Basmanov A. E., Govalenkov S. S. Matematicheskaya model' diffuzii opasnyh himicheskih veshchestv v vozduhe // Problemy nadzvychainykh sytuatsii. 2008. Issue 8. P. 29-39.

14. Terekhov V. I., Teterin I. M., Topol'skiy N. G. Problemy primeneniya vychislitel'nogo intellekta pri planirovanii zadach po predotvrashcheniyu i likvidacii posledstviy chrezvychaynyh situaciy // Materialy XV mezhd. nauchn.-prakt. konf. «Sistemy bezopasnosti». Moscow: Akademiya MCHS Rossii, 2006. P. 49-52.

15. Techniques for Assessing Industrial Hazards: manual. Washington, DC: The World Bank, 1988. No. 55.

16. The HGSYSTEM version 3.0 technical reference manual. Shell Internationale Research Maatschappij BV. Hague, 1994.321 p.

17. GOST P12.3.047-98 SSBT. Pozharnaya bezopasnost' tekhnologicheskih processov. Obshchie trebovaniya. Metody kontrolya.

18. RD 52.04.253-90. Metodika prognozirovaniya masshtabov zarazheniya sil'nodeystvuyushchimi yadovitymi veshchestvami pri avariyah (razrusheniyah) na himicheski opasnyh ob’ektah i transporte. Moscow: Gidrometeoizdat, 1991. 64 p.

19. Arnol'd V. I. Teoriya katastrof. Moscow: Lenand, 2016. 134 p.

20. Mashihina P. B. The distribution modeling of impurities in the atmosphere with taking into account of terrain // Vestnik Dnepropetrovskogo nacional'nogo universiteta zheleznodorozhnogo transporta. 2009. Issue 27. P. 138-142.

21. Karmanov A. G., Knyshev A. I., Eliseeva V. V. Geoinformacionnye sistemy territorial'nogo upravleniya: ucheb. pos. Sankt-Peterburg: Universitet ITMO, 2015. $121 \mathrm{p}$. 